\title{
Migraciones emergentes hacia la Argentina: colombianos y ecuatorianos. Breve panorama y estrategias de inserción cultural ${ }^{\star}$
}

\section{Emergent migrations to Argentina: Colombians and Ecuadorians. Overview and cultural integration strategies}

\author{
Cecilia Melella ${ }^{* *}$ \\ Universidad de Buenos Aires, Buenos Aires, Argentina
}

Recibido: 5 de marzo de 2014. Aprobado: 12 de junio de 2014.

\begin{abstract}
Resumen
Argentina es un país de inmigración. Durante las últimas décadas se han mantenido constantes y/o han aumentado las migraciones de países de la región como Paraguay, Bolivia y Perú. Estas colectividades tienen gran arraigo en el país y poseen una cantidad considerable de asociaciones civiles, religiosas y culturales, y medios de comunicación como periódicos, radios y páginas web. También han desarrollado diversas festividades en la sociedad receptora. Según datos de la Dirección Nacional de Migraciones, cada vez es mayor la cantidad de colombianos y ecuatorianos que migran hacia Argentina en búsqueda de capacitación profesional y educativa. El perfil de estas migraciones se caracteriza por incluir jóvenes que no proyectan una residencia definitiva. El objetivo de este trabajo es describir las particularidades de estos desplazamientos recientes y analizar las estrategias de inserción cultural de estos grupos no demasiado afincados en nuestro país. Recursos como la gastronomía, las prácticas deportivas y culturales y la centralidad de las tecnologías de la información y de la comunicación (TIC) conforman las modalidades de

Este artículo es resultado de mi tesis de Doctorado en Ciencias Sociales "Migración y tecnologías de la información y la comunicación (TIC). De la prensa gráfica a las redes virtuales como espacios de construcción identitaria de los migrantes de países andinos en la Argentina”, Universidad de Buenos Aires. Esta investigación fue financiada por una beca doctoral del Consejo Nacional de Investigaciones Científicas y Técnicas (CONICET).

** Magíster en Comunicación y Cultura, licenciada y profesora en Educación Superior en Ciencias de la Comunicación, Universidad de Buenos Aires (UBA). Docente de Ciclo Básico Común (UBA). Becaria posdoctoral CONICET. Correo electrónico: cemelella@gmail.com
\end{abstract}


inserción elegidas por estos embrionarios colectivos para articular lazos en la sociedad de destino.

Palabras claves: migraciones, migración colombiana y ecuatoriana, inserción cultural.

\begin{abstract}
Argentina is a country of immigration. During the last decades migration rates have remained constant and/or increased from countries in the region, such as Paraguay, Bolivia and Peru. These communities have deep roots in the country and have a large number of civil, religious and cultural associations, media resources like newspapers, radios and websites. They have also developed their own diverse festivities that are celebrated in the host society. According to data from The National Immigration Administration (Dirección Nacional de Migraciones) the number of Colombians and Ecuadorians who migrated to Argentina in search of vocational and educational training is increasing. These migrations are characteristic in that they include young people that don't see themselves with a definitive residence in Argentina. The goal of this paper is to describe the characteristics of these recent migrations and analyze cultural integration strategies of these groups in Argentina. Resources such as gastronomy, sports and cultural practices and the centrality of information communications technology (ICT) are the modalities of integration chosen by these "embryonic collectives" in order to generate networks in the host society.
\end{abstract}

Keywords: migrations, colombian and ecuadorian migration, cultural integration.

\title{
Introducción
}

Argentina es un país que se conformó como receptor de migraciones desde la época de la Colonia. En la actualidad continúan arribando migrantes desde nuevos destinos como Colombia y Ecuador. La sanción de una ley de migraciones más hospitalaria como la 25.871 en 2003, el endurecimiento de las políticas migratorias en Europa desde $2008^{1}$

1 Nos referimos a la sanción, por parte del Parlamento Europeo, de la Directiva Retorno, que promueve la legalización o expulsión de los inmigrantes en su territorio. 
y la crisis económica mundial de los países centrales, en el mismo año, proyectarían un incremento en el país austral de migrantes provenientes de estas dos naciones andinas.

Las migraciones han sido estudiadas desde consideraciones macroestructurales caracterizadas por la centralidad de conceptos como ciudadanía, condición de residencia, tiempo, duración o propósito de la estadía y lugar de nacimiento (Oteiza, 2010). Contrariamente, este trabajo concibe a la migración como consecuencia de un amplio conjunto de factores interrelacionados que incluye circunstancias políticas, económicas y culturales del origen y el destino. Si bien no es una temática inédita dentro del campo de los estudios migratorios, el análisis de la complejidad cultural ha tomado trascendencia en las últimas décadas con estudios provenientes de la etnografía, la geografía cultural y cierta rama de la sociología. Así, más allá de conjeturas globales, entendemos que las migraciones implican procesos de articulación de espacios geopolíticos, culturales y de redes sociales. Estrategias de inserción cultural, birresidencia, remesas y creación de redes (en el contexto del auge de las TIC) son ejemplos de este articulacionismo (Portes, 1978).

El perfil demográfico de los migrantes colombianos y ecuatorianos está compuesto por jóvenes que tienen como objetivo estudiar y capacitarse en Argentina, por lo cual, su radicación en el país no es, en su mayoría, definitiva. Pese a la situación de fugacidad, estos migrantes han desarrollado prácticas sociales diversas cuya dimensión cultural implica una diferencia situada que sienta las bases para la identificación de cada grupo. Estas prácticas, entendidas como estrategias de inserción cultural (Altamirano, 1983) ${ }^{2}$ en la sociedad de destino, implican negociaciones y conflictos y promueven relaciones inter e intraculturales (Appadurai, 2001).

Elementos culturales como la lengua, las fiestas cívicas y religiosas, la gastronomía, la música y los bailes se reconstituyen como estrategias de supervivencia, de interacción y convivencia de los migrantes internacionales en la sociedad de destino (Sassone, 2006; Melella, 2012, entre otros). La gastronomía étnica, los microemprendimientos, los medios de comunicación de migrantes y las actividades culturales y recreativas son las principales prácticas que intensivamente desarrollan estos nuevos migrantes que los incorporan en la sociedad argentina y remarcan su etnicidad como forma de identificación y sentimiento de pertenencia (Barth, 1976). Asimismo, debido a la composición etaria de estas migraciones (20 y 35 años), el uso de las tecnologías de la información y de la comunicación (TIC), en especial Internet, se conforma como una nueva herramienta

2 La inserción cultural la comprendemos en términos de integración y no de asimilación, si bien el primer concepto no deja de ser controversial. La inserción implica, entonces, la inclusión de la diferenciación cultural dentro de un sistema de unidad social cobijado por el Estado-nación (Malgesini y Giménez, 2000). 
útil a la hora de desarrollar redes de articulación y estrategias de inserción, intercambio y circulación cultural en contextos migratorios (Melella, 2013a). En este sentido, nos interrogamos por el lugar que ocupan las estrategias de inserción cultural en un contexto global marcado, por un lado, por la fugacidad en las relaciones sociales, y, por otro, por la interconexión que es consecuencia del auge de las tecnologías de la información. Nos preguntamos por la trascendencia de estas prácticas culturales en el desarrollo social, cultural y económico de las comunidades y por su capacidad para la generación de espacios interculturales marcados por la horizontalidad y el intercambio en y con la sociedad de destino.

Así, el objetivo de este artículo es exponer las estrategias de inserción cultural desarrolladas por los migrantes colombianos y ecuatorianos en la Argentina desde una óptica comparativa que involucra migraciones sur-sur. Para dicha tarea empleamos una metodología cualitativa que contempló el análisis de discurso y contenido de fuentes primarias y el trabajo hermenéutico con fuentes secundarias. Partimos de considerar a los discursos emitidos por estos grupos migratorios como textos a ser abordados a partir de la búsqueda de elementos textuales y paratextuales de periódicos y páginas web (Steimberg, 1993; Verón, 1993; entre otros). Asimismo, contemplamos el análisis de las entrevistas en profundidad llevadas a cabo a diferentes referentes de cada colectividad. La entrevista, en su forma dialógica, hace del encuentro entre sujetos una escena fundante para esta investigación. Esta herramienta metodológica nos permite recuperar la voz del otro, adentrarnos en cada trayectoria migratoria y reconstruir el espacio biográfico delineado por cada sujetos o grupo (Arfuch, 2010). Por último, pese a que resulta escasa, tuvimos en cuenta el análisis hermenéutico de la bibliografía sobre estas migraciones en la Argentina.

El artículo se proyecta sobre apartados descriptivos e interpretativos. En primer término describimos, de forma concisa, la historia de las migraciones hacia la Argentina. En los apartados siguientes se detallan las migraciones colombiana y ecuatoriana a nivel mundial, focalizando en sus principales características. En estas últimas referimos las particularidades de la migración hacia Argentina y resaltamos las estrategias de inserción cultural que desarrollan estos grupos en el país. 


\section{Breve panorama sobre la historia de las migraciones internacionales en Argentina}

Las migraciones inter e intracontinentales han sido y son un rasgo característico de América, en general, y de la República Argentina, en particular. Hace más de cinco siglos que comenzó un arribo sistemático de poblaciones al continente americano que sintetizamos en cuatro etapas principales dentro del proceso migratorio internacional en América Latina y el Caribe (Pellegrino, 2010): 1) el período colonial, 2) el período independiente, 3) la transición demográfica y 4) los cambios migratorios, la crisis económica y la globalización.

Durante el período colonial, el traslado de poblaciones desde las metrópolis tuvo como meta consolidar la ocupación del territorio americano bajo el dominio de los aborígenes y el fortalecimiento de la empresa colonizadora. Además, se promovió la inmigración forzada de poblaciones del África para ser utilizadas como esclavos.

Desde la segunda mitad del siglo XIX y en los años posteriores a las guerras de la independencia (período independiente), las repúblicas latinoamericanas se propusieron atraer poblaciones europeas a fin de vincular a la región con el resto del mundo en un marco de apertura al intercambio comercial. En Argentina, la Generación del Ochenta ${ }^{3}$ favoreció este tipo de inmigración para impulsar el crecimiento demográfico del país y obtener mano de obra desvalorada que cultivara las tierras y realizara obras públicas. El objetivo principal era hacer del país un territorio europeizado que pudiera ingresar como proveedor de materias primas en el sistema económico mundial. Este aumento en la población tuvo como consecuencia la concentración de la masa inmigratoria en las ciudades portuarias o litorales como Buenos Aires o Santa Fe, donde los extranjeros se instalaron como comerciantes, obreros ferroviarios, portuarios o trabajadores de los frigoríficos.

Alrededor de 56 millones de personas integraron el movimiento de emigración intercontinental que tuvo lugar entre 1821 y 1932. El 60\% partió hacia los Estados Unidos de Norteamérica, el 22\% hacia América Latina, el 9\% hacia Canadá y el otro 9\% hacia Australia, Nueva Zelanda y Sudáfrica. De los 12 millones de personas cuyo destino fue América Latina, la mitad se dirigió a la Argentina, 36\% al Brasil, 6\% al Uruguay y 7\% a Cuba; el pequeño saldo restante se distribuyó en cantidades menores entre otros países

3 Además, hubo, por lo menos, dos posiciones contrapuestas representadas en los proyectos del jurista Juan Bautista Alberdi, considerado autor intelectual de la Constitución argentina de 1853 y del ex-presidente Domingo Faustino Sarmiento (Devoto, 2004). 
latinoamericanos. De los que llegaron a América Latina, a lo largo de ese período de cien años, el $38 \%$ fueron italianos, el $28 \%$ españoles, el $11 \%$ portugueses, el 2,8\% franceses y el 2,7\% alemanes (Calderón Chelius citada por Pellegrino, 2010, p. 31).

Como queda plasmado en la cita anterior, cerca de la mitad de los inmigrantes retornó a su país de origen. Buenos Aires, hacia finales de siglo, tenía casi la mitad de la población que había arribado del extranjero en una primera instancia.

A partir de los años 30 se inició una transición demográfica en la mayor parte de los países latinoamericanos. El pasaje del modelo agroexportador al modelo de sustitución de importaciones produjo grandes movilizaciones de poblaciones desde zonas rurales a urbanas. Este movimiento demográfico provocó un vertiginoso crecimiento de las ciudades latinoamericanas. Argentina dejó de ser un destino prioritario para los migrantes intercontinentales, pero se mantuvo como destino para el arribo de los intracontinentales, en especial de los pobladores provenientes de países limítrofes, convirtiéndose en el corazón del sistema migratorio del cono sur.

Simultáneamente, se produjeron migraciones internas de zonas rurales hacia las grandes ciudades. La causa principal de esta migración se debió a la demanda de mano de obra estacional de las economías regionales del interior del país. "Hasta los años 60, todos los movimientos de migración internacional con un volumen superior a las 50.000 personas presentan un carácter fronterizo..." (Pellegrino, 2010, p. 37). Sin embargo, la población migrante se comenzó a concentrar en el conurbano bonaerense y en la ciudad de Buenos Aires dejando las zonas de frontera, dando lugar a lo que Susana Sassone (2006) pertinentemente denominó como metropolización de las migraciones. Este desplazamiento a zonas centrales, sumado al aumento de los inmigrantes de países limítrofes por sobre el número de extranjeros de otros orígenes, "ha generado su mayor visibilidad social y ha promovido los discursos políticos, institucionales y mediáticos que advierten al respecto" (Caggiano, 2005, p. 52).

Avanzada la década del 60, comenzó a ser cuestionado el modelo de sustitución de importaciones y se inició una etapa de librecambio y apertura al mercado internacional. La crisis del petróleo de los años 70 y las consecuencias internas de la deuda externa tuvieron como corolario la caída del Producto Bruto Interno (PBI) per cápita, el deterioro del nivel de vida de los sectores medios y un alza en los niveles de pobreza e indigencia. El desempleo y la informalidad laboral se convirtieron en fenómenos estructurales y produjeron una paralización de las migraciones regionales hacia nuestro país. Sin embargo, 
es pertinente destacar que durante los años 70 y 80 se desplegaron otras migraciones en Latinoamérica vinculadas a la violencia política.

A partir de la década del 90, los procesos migratorios se desarrollaron en un contexto de aplicación de políticas neoliberales, en un período caracterizado por los cambios migratorios, la crisis económica y la globalización. A diferencia de los modelos anteriores, que necesitaban de mano de obra para el progreso agropecuario e industrial, para el neoliberalismo los trabajadores extranjeros no eran primordiales en el desarrollo del proyecto nacional (Grimson, 1999). Sin embargo, la proporción de los migrantes limítrofes en la población argentina no registró variaciones a lo largo del siglo XX y marcó una tendencia a elevarse hacia 1991 como consecuencia de la sobrevaloración del peso argentino con respecto a otras monedas (Castillo y Gurrieri, 2012).

Es para destacar que durante el último período mencionado se sancionó, en el 2003, la Ley de Migraciones 25.871 (Ley Giustiniani), que conceptualizó a la migración como derecho humano, contemplando como derechos la reunificación familiar, el acceso a servicios sociales, la participación en la vida pública y la identidad cultural (Novick, 2008).

En cuanto a la región, durante la década del 70 hubo un gran aumento de la migración intralatinoamericana, que permaneció estable durante los años 80 y 90 aunque presentaron un modesto incremento hacia 2000 (Martínez, 2003 y 2011). En este contexto, las migraciones andinas dejaron de ser transfronterizas y a nivel mundial se fortalecieron los destinos extracontinentales como España o Japón (Organización Internacional de las Migraciones OIM, 2012). En este sentido, es ilustrativo el caso de la migración peruana hacia Argentina, que se incrementó notoriamente durante la década de 1990 y 2000, pasando de un total de 88.260 personas en 2001 a 157.514 en 2010 (Instituto Nacional de Estadística y Censos INDEC, 2001, 2010).

Ya entrada la década del 2000 comenzaron a arribar a la Argentina personas provenientes de otros destinos como Colombia y Ecuador. En 2012 las radicaciones colombianas aumentaron 13 veces el registro de 2004 ( 235 en 2004 a 3.036 en 2012). Las radicaciones ecuatorianas multiplicaron 7,5 veces el registro de 2004 ( 82 en 2004 a 616 en 2012) (Tabla 1). Es decir, durante 2012 Colombia ocupó el cuarto puesto (luego de Paraguay, Bolivia y Perú) en el ranking de radicaciones permanentes resueltas en Argentina, mientras que Ecuador tomó el octavo puesto (después de Chile, Brasil y Uruguay). 
Tabla 1

Radicaciones permanentes resueltas por año.

Países limítrofes más Colombia y Ecuador (2004-2012)

\begin{tabular}{lcccccccccc}
\hline Países & 2004 & 2005 & 2006 & 2007 & 2008 & 2009 & 2010 & 2011 & 2012 & Total \\
\hline Paraguay & 5.002 & 6.377 & 4.310 & 9.488 & 26.009 & 33.867 & 37.808 & 57.034 & 56.635 & 236.530 \\
Bolivia & 2.013 & 5.447 & 8.578 & 18.434 & 29.005 & 28.980 & 27.531 & 36.331 & 31.963 & 188.282 \\
Perú & 4.245 & 2.368 & 4.883 & 10.877 & 13.931 & 12.382 & 14.949 & 17.284 & 17.909 & 98.828 \\
Brasil & 570 & 486 & 694 & 804 & 1.382 & 1.789 & 2.517 & 3.675 & 4.260 & 16.177 \\
Chile & 698 & 567 & 1.023 & 1.353 & 2.095 & 2.330 & 2.078 & 1.990 & 2.060 & 14.194 \\
Uruguay & 967 & 752 & 884 & 1.087 & 2.101 & 1.962 & 104 & 1.809 & 2.065 & 11.731 \\
Colombia & 235 & 173 & 308 & 662 & 685 & 1.221 & 1.676 & 2.733 & 3.036 & 10.729 \\
Ecuador & 82 & 65 & 176 & 394 & 336 & 517 & 533 & 514 & 616 & 3.233 \\
\hline
\end{tabular}

Fuente: Elaboración personal sobre datos de la Dirección Nacional de Migraciones, 2012.

\section{La migración colombiana}

La migración colombiana hacia Argentina es, como señalamos, un fenómeno reciente. En 2001 se registraban 3.713 pedidos de radicación de colombianos en el país, pero en 2008 se registró un aumento del 66,5\% (5.584 personas). En 2010 las solicitudes treparon a 16.442 y posicionaron a Colombia en el cuarto lugar. Por su parte, las radicaciones permanentes resueltas fueron 3.036 y las temporarias 12.354 (Tabla 1), cifras que advierten el predominio de los temporarios que llegan para estudiar y/o capacitarse, al ofrecer Argentina la posibilidad de realizar estudios universitarios o de posgrado de manera gratuita o a bajo costo. Por otra parte, no hay que olvidar que Colombia es el quinto país a nivel mundial en la emisión de refugiados víctimas de la violencia armada (Garay y Rodríguez, 2005; Cárdenas y Mejía, 2006). 


\section{Etapas de la migración colombiana}

Colombia ha tenido históricamente poca movilidad internacional de población, aunque esta ha aumentado desde finales de la década del 80 . El advenimiento de una mayor tendencia a la emigración reside en la pluralidad de los orígenes regionales y sociales de los nuevos migrantes y en la multiplicidad de posibles itinerarios y destinos (Ramírez, Zuluaga y Perilla, 2010).

Las migraciones colombianas pueden ser divididas en tres oleadas (Puente, 2011): 1) 1960-1970: migración compuesta por profesionales y universitarios cuyos destinos principales eran Venezuela, Estados Unidos, Panamá y Ecuador. A mediados de los años 70 el flujo de migrantes comenzó a diversificarse a obreros no calificados, comerciantes y empresarios de clase media; 2) 1980-1990: las dificultades económicas y el tráfico de drogas desarrollaron una nueva oleada migratoria relacionada con la necesidad de contar con distribuidores para este producto. Estados Unidos fue la plaza principal; 3) 1990-2010: se produjo un aumento de las migraciones a causa de la crisis económica y de la intensificación del conflicto armado. Nuevamente los principales destinos fueron Estados Unidos, España, Venezuela y Ecuador.

En la década del 70 comenzó el proceso de incremento de la emigración que trepó a escalas muy superiores en la década del 90 y 2000 (la cantidad de emigrantes fue de 442.092 en la década del 70, 925.318 en la década del 80 y de 2.665.293 en el período comprendido entre 1990 y 2005) (Ramírez et al., 2010). Los destinos más elegidos para 2000 fueron: Venezuela (604.691), Estados Unidos (509.872) y España (174.405). Durante el período 2001-2005, España se convirtió en el primer destino $(29,1 \%)$ por sobre Estados Unidos (27,0\%), Venezuela $(17,3 \%)$ y Ecuador $(4,4 \%)^{4}$. En 2008 se registró una cantidad total de 4.167.388 colombianos en el exterior. Los tres destinos principales siguieron siendo Estados Unidos (722.269 personas), Panamá (252.353) y España (177.413). Argentina ocupó el puesto número siete con una cantidad de 54.020 migrantes detrás de Ecuador, Perú y México (Ramírez et al., 2010).

4 En 2001 España y Colombia celebraron el "Acuerdo para la Regulación y Ordenación de Flujos Migratorios Laborales", a través del cual 8.115 trabajadores viajaron a España entre 2001 y 2008. En 2008 se sancionó en el Parlamento Europeo la Directiva Retorno, que promovió la legalización o expulsión de los inmigrantes en su territorio. Contrariamente, en 2014, por ejemplo, la provincia canadiense de Quebec situó a los colombianos en su lista preferencial de ciudadanos a instalarse en dicha región debido a que existe allí una población de 25.000 nacionales. 


\section{La peculiaridad de la migración forzada}

La mayor parte de las migraciones internas de este país andino corresponde a la migración forzada, es decir, a formas de movilidad humana que responden a presión externa y ocurren bajo coerción (Hernández, 2010). El desplazamiento forzado de la población es provocado por actores armados como las guerrillas, los grupos de narcotraficantes o los paramilitares. En Colombia hay más de 3.000.000 de desplazados internos y cerca de 300.000 que han buscado refugio en países vecinos como Ecuador, Venezuela y Panamá u otros más distantes como Estados Unidos, Canadá y Costa Rica. Si bien el desplazamiento forzado en Colombia tiene raíces históricas (en especial, a mediados del siglo XX), en los años 80 se asoció directamente al conflicto armado entre los actores antes mencionados por el dominio de territorios geoestratégicos. Asimismo, esta geografía del desplazamiento comprende territorios históricamente excluidos de los beneficios del desarrollo, situación que ha dejado sumida en la pobreza a más de la mitad de la población, en especial, a los sectores más vulnerables como indígenas y campesinos (Villa, 2008).

Según el Alto Comisionado de las Naciones Unidas para los Refugiados (ACNUR), en 2009 el número de colombianos en situación de refugiado y similar fue de 389.753. Para 2012 la cantidad se mantuvo estable con un total de 394.100.

Con todo, el forzamiento a emigrar también puede ser causado por motivos económicos y laborales e igualmente encaminado hacia destinos lejanos como España, Estados Unidos o hacia países que provean más opciones para el desarrollo profesional (Cárdenas y Mejía, 2006). Generalmente, la migración laboral se dirige a países desarrollados con el objeto de obtener un mayor progreso personal y poder ayudar a la familia a través del envío de remesas. Un $85,7 \%$ de los emigrantes colombianos ha partido por razones económicas y laborales hacia destinos que responden al eje sur-norte (Estados Unidos, España e Inglaterra), aunque también es fuerte la línea sur-sur representada por Venezuela.

Con respecto a la emigración voluntaria, esta puede ser producida por razones económicas y laborales o por motivos de perfeccionamiento académico y profesional. $\mathrm{Si}$ bien ambos tipos han crecido en los últimos años, la migración laboral forzada es más cuantiosa al instalarse como respuesta al aumento de la pobreza y del desempleo que sufre Colombia (al igual que la mayoría de los países latinoamericanos), consecuencia de la puesta en práctica de políticas neoliberales como las privatizaciones, la minimización del gasto social en salud y educación, la flexibilización laboral, etcétera. Como señala Guarnizo: 
La emigración masiva de colombianos, de manera especial desde finales de la década de los ochenta, ha transformado profundamente las estructuras sociales, culturales y políticas de Colombia. El argumento que sostiene este artículo es que estas transformaciones han convertido, al país, en una formación social transnacional. Lo cual significa que las múltiples matrices de poder (político, económico, social) que estructuran a la sociedad, así como a la producción, reproducción y transformación de la cultura que modela la identidad nacional, trascienden la jurisdicción territorial nacional y tienen lugar en un espacio transnacional en el cual los que viven «acá» (los residentes dentro del territorio nacional) interactúan con, influencian a, y son influenciados por los que viven «allá» (los colombianos residentes en múltiples destinos extranjeros). Mientras tanto, los que viven allá van construyendo relaciones fluidas que conectan diversas localidades de asentamiento colombiano en el exterior (2006, p. 81).

\section{Colombianos en la Argentina: los motivos para migrar}

La migración colombiana en Argentina es un acontecimiento naciente y está motivada principalmente por razones educativas y profesionales ${ }^{5}$. Esta migración está compuesta por población joven (entre 18 y 35 años) que procede de las principales ciudades colombianas y es calificada: estudiantes universitarios de áreas vinculadas a la publicidad, cine, diseño, ciencias sociales y salud. El testimonio ilustra los motivos que los colombianos tienen para migrar hacia Argentina.

Llegué aquí a principio de 2010, en febrero. Vine a hacer una maestría, ya que soy licenciado en Química de la Universidad Distrital de Bogotá (...) Busqué (la maestría) en muchos lugares, México, España, Chile y Brasil, y por supuesto en Argentina, que era la opción más económica respecto a otras universidades públicas (...). También por el reconocimiento de la UBA (Universidad de Buenos Aires), que a nivel latinoamericano está muy bien posicionada, pero bueno, fue por la parte educativa, económica, cultural (Ministerio del Interior y Dirección Nacional de Migraciones, p. 186).

5 También entre las personas que emigran hacia Argentina se destacan los refugiados. En este trabajo no abordaremos específicamente esta problemática ya que excede los objetivos propuestos. Para obtener un panorama más amplio sobre refugiados colombianos en la Argentina ver: Hernández, M. (2011). Colombianos en Argentina: memorias del conflicto armado y experiencia migratoria. 
Es una población que viene a capacitarse bajo diferentes programas de becas como las del Instituto Colombiano de Crédito y Estudios Técnicos en el Exterior (ICETEX) ${ }^{6}$. También utilizan otras estrategias para costear su capacitación, como la inserción laboral en la sociedad de destino en el rubro gastronómico - camareros a microemprendedores - y/o trabajadores en servicios y en ventas - call centers - (Duque y Raffani, 2009). Son numerosos los microemprendimientos de venta de comida colombiana por la web, en especial por Facebook. Algunos ejemplos: Arepas en Baires, Mercadito Colombiano, Arepas Comeme en Baires y Arepas Empanadas Colombianas La Tata, entre otros.

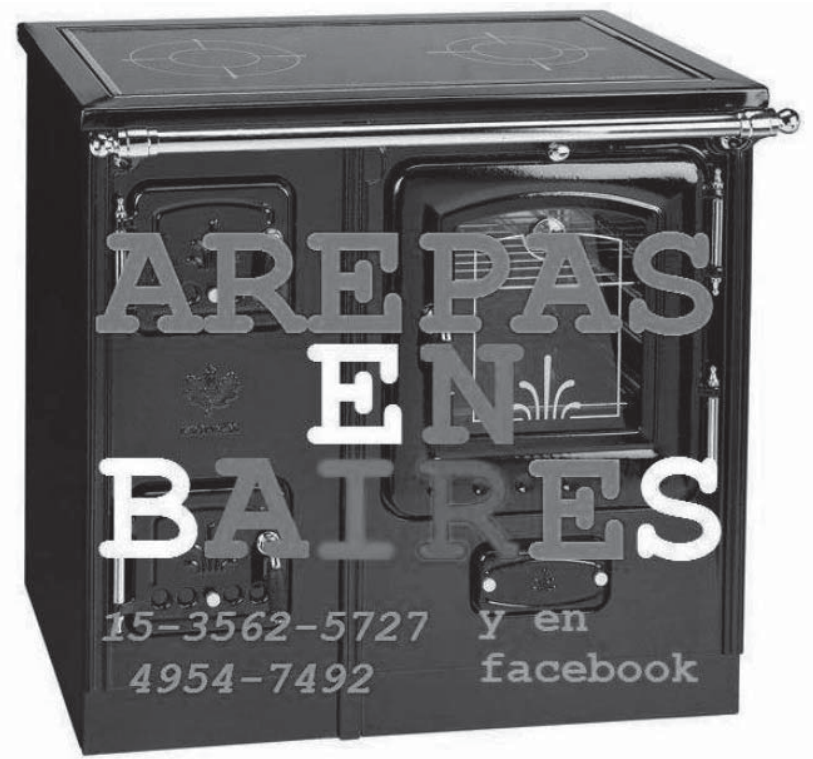

Figura 1. Microemprendimiento de estudiante colombiano en Argentina. Fuente: Facebook de Arepas en Baires.

6 La OIM cuenta con un Programa de Apoyo a Estudiantes y Becarios en el Exterior que ha favorecido, desde 2003, a 16.309 colombianos, principalmente en España, a culminar sus especializaciones de posgrado (Ramírez et al., 2010). 


\section{Estrategias de inserción cultural de colombianos en la Argentina}

Al ser una migración joven, los colombianos han desarrollado diversas estrategias de inserción cultural en la sociedad de destino, en este caso, Argentina. Destacamos cuatro: la gastronomía étnica; el desarrollo de microemprendimientos; los medios de comunicación, en especial, los que funcionan por la red Internet; y las actividades culturales y recreativas. Estas estrategias construyen una red de articulación en tanto espacios con presencia de migrantes (Portes, 1978) que promueven la convivencia dentro del tejido social y, tanto para los nativos como para los migrantes, implican relaciones conflictivas que conllevan modos de aprendizaje, tolerancia y regulación de estas nuevas situaciones.

La gastronomía étnica es un rubro que se ha exacerbado en la reciente década en la Argentina con restoranes de diversas colectividades como la mexicana, la japonesa, la peruana, entre otras. Los colombianos no escapan a esta regla y, en los últimos años, se han fundado diversos comercios gastronómicos, principalmente en Buenos Aires, como: Colombia mía, Epa la Arepa, Corronchos, Antojito colombiano, Tierra colombiana, Los recuerdos, Todo Colombia, La guitarrita y Gabocolombian, entre otros. La mayoría se encuentra en los barrios porteños de Palermo, Recoleta o Almagro, circuito caracterizado por el turismo nacional e internacional. Estos comercios ofrecen una carta con comida típica del país andino orientada al cliente que gusta de los platos gourmet $\mathrm{y}$, en menor medida, a los connacionales que viven en la Argentina. La gastronomía conecta simbólicamente el allá con el aquí y articula posibles relaciones interculturales en las sociedades transnacionales (Melella, 2012). Asimismo, los microemprendimientos también tienen que ver, en gran parte, con la oferta gastronómica, la reventa de bienes ordinarios como indumentaria o electrodomésticos (usados, que dejan aquellos que regresan a su patria) y con los productos de origen colombiano. La web (páginas o cuentas de Facebook) es la plataforma elegida para publicitarlos dada su accesibilidad, su maleabilidad, su instantaneidad y su gratuidad (Diminescu, 2011; López y Ciuffoli, 2012). Así, se configuran redes transnacionales (espacios) vinculadas a las prácticas migratorias (transnacionales) (Levitt, DeWind y Vertovec; 2003; Pedone, 2005; Portes, 2005).

Por otra parte, los medios de comunicación de migrantes cumplen un papel esencial para la socialización de estos grupos en las sociedades receptoras. Los diasporic media (medios de la diáspora) o minority media (medios de las minorías) han respondido a la suplencia de demandas de información específica sobre sus países de origen, de datos prácticos para vivir en la sociedad de acogida, así como indicaciones sobre procedimientos administrativos, leyes o prácticas sociales en general (Gómez-Escalonilla, 2008). 
La prensa de colectividades inmigrantes en la Argentina contemporánea posee distintas funciones como ser un medio de información y de opinión, un medio solidario y de asistencia jurídica, social y cultural al migrante (medio de servicio), un medio alternativo y contrainformacional y un espacio de conformación de identidades (Melella, 2012). Asimismo, estos medios gráficos funcionan como lazos de cohesión interna dentro de cada colectividad y como recursos de visibilidad en las sociedades receptoras (Gómez, 2009; Baby Collin, Cortes, Miret y Sassone, 2010). Por último, también se conforman como comercios o negocios étnicos al desempeñarse como pequeñas empresas que suministran bienes y servicios dentro de una comunidad étnica, nacional o religiosa (Cavalcanti, 2008).

Los colombianos han editado dos publicaciones gráficas de renombre en Argentina: El Colombiano, publicado bajo el auspicio de la Embajada de Colombia en la Argentina y dirigido por Hernando Pastrana Borrero, embajador de Colombia en el país durante la década de 1990, y Correo Colombiano, una publicación independiente dirigida por Gari Gazán Caballero, que se editó desde 1994 hasta mediados de la primera década de 2000. Durante los años 2013 y 2014 se han refundado algunos diarios entre los que se destaca CambalaCHE, el periódico, realizado ad honorem por un grupo de colombianos residentes en Buenos Aires.

El uso del Internet, con páginas web o cuentas de Facebook, ha reemplazado y/o complementado las funciones de los periódicos de migrantes. Estos sitios virtuales se han convertido en nuevos protagonistas en la conformación y funcionamiento de las redes sociales, por lo general, sin la intervención y/o mediación del Estado, y han brindado soporte a las transformaciones políticas, familiares, comunitarias, culturales y económicas en los grupos migratorios transnacionales (Canales y Zlolnski, 2000; Portes, 2005; entre otros). Internet supera a los periódicos al proporcionar la posibilidad de conexión instantánea y permitir la creación de esferas públicas en la diáspora que concentran los imaginarios y las problemáticas del origen, del destino y las experiencias del desplazamiento (Appadurai, 2001). La diáspora que promueven estos nuevos medios trasciende la idea de que la acción en el migrar, vinculada a la territorialidad, es el eje central para la construcción de vínculos transnacionales (Cortéz, 2004). A su vez, Internet es un espacio que, debido a su bajo costo de comunicación, posibilita la coordinación de acciones en grupo utilizando pocos recursos y, a diferencia de la prensa gráfica, dada su constitución tecnológica, la red virtual se conforma como una red social más transparente y presenta una mayor accesibilidad a la información. 
Los colombianos en Argentina responden a un tipo de migración reciente y no poseen numerosas asociaciones con espacio físico, pero sí con presencia en la web. En 2013 relevamos ocho sitios web de asociaciones colombianas en la Argentina: cuatro son asociaciones civiles orientadas a brindar información a migrantes temporarios, en general, estudiantes; dos son emprendimientos comerciales; un sitio se engloba dentro de la categoría medios de comunicación y el último es una web oficial de la Embajada de Colombia en Argentina. Así, aparte del deseo de cambiar de contexto político y social y de la vasta oferta cultural argentina, la conformación de una red social (virtual) ayuda a tomar la decisión de migrar hacia este destino. Páginas de Internet como ColArgentina, Colombianosenargentina.com, Colombianos Sin Garantía o Colombianos Rumberos en Argentina, Asociación de Mujeres Colombianas en Argentina, entre otras, desarrollan estrategias residenciales que van desde compartir vivienda con amigos o conocidos, recomendar inmobiliarias o dar información sobre derechos y contratos de locación. La Asociación de Mujeres Colombianas en Argentina (AMCA), una de las más representativas y antiguas, tiene como objetivo "integrar a la comunidad colombiana y facilitar los medios para su mejor adaptación al sistema de vida argentino, así como la difusión de la cultura y costumbres colombianas" (Sitio web de la Asociación de Mujeres Colombianas en Argentina http://amcaweb.com.ar/institucional/equipo/). Así, sus proyectos se proponen financiar microemprendimientos, realizar acciones sociales y solidarias y difundir la cultura del este país andino.

Por su parte, Facebook presenta un panorama más frondoso: hemos relevado más de 40 cuentas de colombianos en Argentina que incluyen asociaciones de residentes, microemprendimientos, grupos abiertos de estudiantes, actividades culturales y deportivas, entre otras. El uso de esta plataforma permite subvertir las limitaciones espacio-temporales y mantener vínculos con el espacio simbólico y social del origen, así como establecer conexiones (reales y virtuales) con sus connacionales en destino, en la diáspora colombiana y con la sociedad receptora en general (Melella, 2013a). 


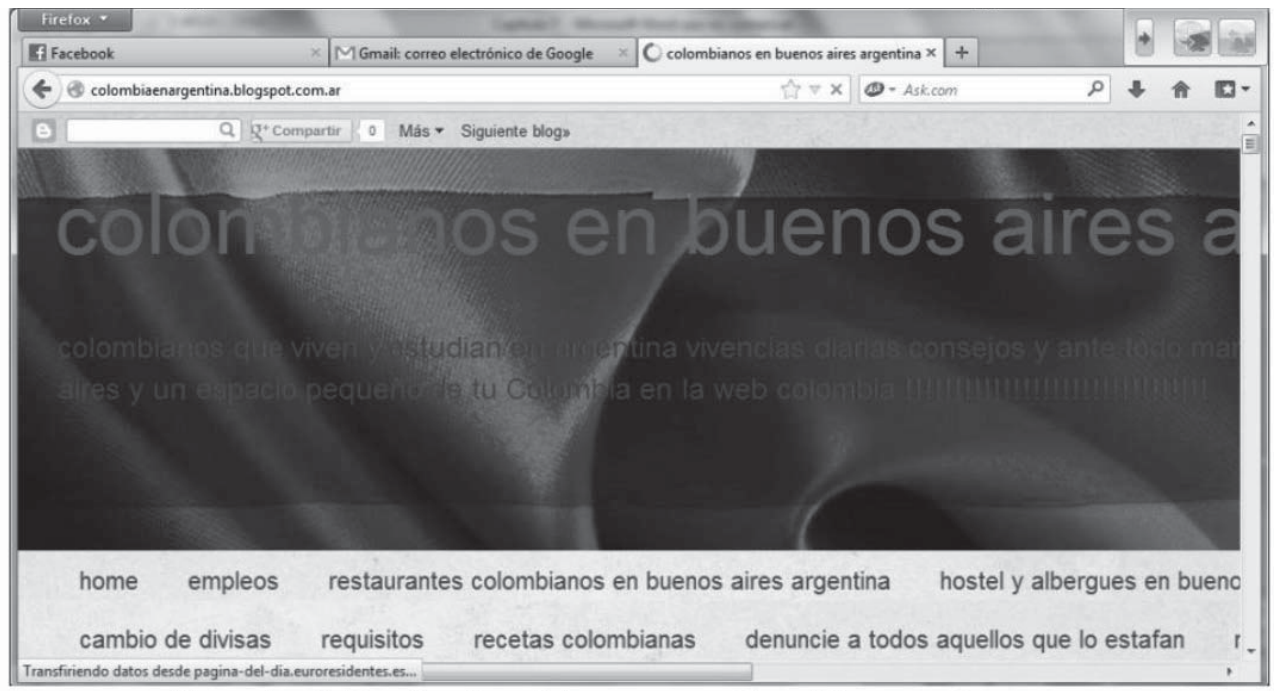

Figura 2. Colombianos en Buenos Aires, Argentina. Fuente: http://colombiaenargentina. blogspot.com.ar

Por sobre la inserción laboral y residencial existen diversas prácticas sociales que tienen que ver con el tiempo libre y vinculan a estos jóvenes migrantes con la sociedad receptora y entre ellos como colectivo. La "movida cultural" que ofrece Buenos Aires, con su gran oferta de cursos de perfeccionamiento, idiomas, teatro, etcétera, así como las fiestas temáticas de la misma colectividad - donde predomina la música colombiana - o la realización de distintas actividades por el movimiento político colombiano en el exterior, constituyen modos de socialización de estos migrantes.

Con todo, gran parte de estos nuevos habitantes, en los momentos de esparcimiento, no siempre se reúnen con sus connacionales, sino que prefieren relacionarse con la cultura argentina. Esto podría deberse a dos motivos: por un lado, viven la migración como de corta duración e intentan absorber lo máximo posible de la cultura de la sociedad de destino; por otro lado, tienen cierta desconfianza o prejuicios de ellos mismos relacionadas con su historia de violencia y con la necesidad de saber quién es quién (Puente, 2011). 
Por último, el retorno se realiza una vez terminado el proceso de estudios con la intención de insertarse en la sociedad de origen, aunque muchas veces se presenta la posibilidad de permanecer en la Argentina o de emigrar a otros destinos. Sin embargo, la falta de oportunidades laborales en la Argentina, los vínculos familiares, la inserción laboral o la manutención de los trabajos que tenían en Colombia antes de partir, hacen que la mayor parte de los jóvenes colombianos retornen a su tierra natal (Puente, 2011; Melella, 2013a).

\section{La migración ecuatoriana}

Los principales destinos de la migración ecuatoriana han sido España, Estados Unidos e Italia (OIM, 2011). El perfil de estos migrantes comprende personas jóvenes con un alto nivel educativo que provienen de las ciudades. Las causas de la migración son generalmente económicas. Esta se caracteriza por una fuerte feminización (Pedone, 2005). La migración hacia los países sudamericanos es considerablemente menor si la comparamos con los tres países antes citados. Dentro de este conjunto, Chile, Colombia y Venezuela son los destinos más requeridos (Herrera, Moncayo y Escobar, 2011). Argentina figura en el puesto número cuatro entre los sudamericanos y la población que atrae este país del cono sur está compuesta por estudiantes cuyo objetivo es capacitarse en las universidades locales.

\section{Etapas de la migración ecuatoriana}

Como en el caso de los colombianos, el hecho de migrar no es una práctica ajena para el pueblo ecuatoriano. Desde la década del 60 se han conformado redes transnacionales que han incluido el flujo de personas, de dinero, de información y han conectado comunidades locales con América del Norte, América Latina y, desde hace pocos años, con Europa. Actualmente, la diáspora ecuatoriana se encuentra en más de 55 países (Herrera et al., 2011; Oleas y Hurtado, 2011). Ecuador ha experimentado dos grandes olas de migración internacional. La primera tuvo su punto álgido en los años 60 y la segunda en los 80 y en ambas el destino principal fue Estados Unidos. En 20 años, los ecuatorianos pasaron de ser una colectividad anónima a convertirse en una de las más numerosas, por ejemplo, de la ciudad de Nueva York (Jokisch y Kyle, 2005). 
En la clausura de los años 90, Ecuador, al igual que otros países latinoamericanos, sufrió una crisis política y económica que comenzó en 1998 y que le produjo uno de los empobrecimientos más acelerados de América Latina, solo comparable con el caso argentino. Entre 1996 y 2000, el país andino tuvo cinco presidentes en cinco años y enfrentó la devaluación de su moneda, el PBI cayó y una crisis bancaria paralizó el sistema financiero. La pobreza y la desocupación fueron en aumento: en 1995 el 7\% de la población estaba desempleada, en 1997 el 9\% y en 1999 el 15\%. El crecimiento de la pobreza dentro del grupo de asalariados y en áreas urbanas vislumbró en la migración internacional una de las soluciones más certeras.

En un intento desesperado por salvar su cargo, el presidente Manhuad anunció sus planes de dolarizar la economía en el año 2000. Luego de su caída y de su reemplazo por Gustavo Noboa, se dio paso a la dolarización ecuatoriana y los créditos stand-by del FMI obligaron a las autoridades económicas a tomar medidas de austeridad. El aumento de los índices de pobreza, inflación y desempleo, agravado por el "congelamiento" o pérdida de los ahorros en la banca privada de la población, obligó a miles de ecuatorianos, mujeres en su mayoría, a migrar a España. Lo hicieron en calidad de turistas, y con la ayuda de las agencias de viaje más importantes del Ecuador, en buena parte. Una reorientación radical de la migración ecuatoriana ocurrió en un período de dos años, en 1998, pocos ecuatorianos vivían en España, pero para 2002 se calculan 200.000 y otros miles en Italia, Francia, Inglaterra y los Países Bajos. Para el 2005, la población ecuatoriana se ha duplicado nuevamente en España y suman más de 400.000 (Jokisch y Kyle, 2005, p. 58).

La mayoría de los emigrantes (56\%) viajaron para buscar empleo (es decir, antes de viajar eran desempleados) y solo una pequeña parte (20\%) emigró con el objetivo de mejorar sus ingresos (Serrano, 2008) ${ }^{7}$.

\section{La estampida ecuatoriana}

Según información de la Dirección Nacional de Migración de Ecuador, entre el 2002 y 2007 un total de 766.888 ecuatorianos salieron con destino a España ${ }^{8}$, mientras

7 Según el Ministerio de Trabajo del Ecuador, se calcula que, en 2008, un 10\% de la población económicamente activa se encontraba fuera del país. El Banco Central del Ecuador estima que, en la actualidad, más de dos millones de ecuatorianos residen en el exterior.

8 Así lo demuestran los datos proporcionados por el Ministerio de Trabajo y Asuntos Sociales de España, según los cuales, para junio de 2007, 430 ecuatorianos tenían certificado de registro o tarjeta de residencia en este país, convirtiéndose en el tercer grupo de extranjeros después de los marroquíes y rumanos. 
que 1.124.901 emigraron hacia los Estados Unidos. Otros destinos notorios fueron Colombia, Perú, Argentina, Cuba, Brasil, México, Panamá y Venezuela. Sin embargo, la emigración ha fluctuado bastante en los últimos años: en 2000 se registró la salida de 504.203 personas, la entrada de 355.836 proporcionando un saldo migratorio negativo de 148.367. Por el contario, en 2007 la salida fue de 795.083 personas, la entrada de 752.684 y el saldo negativo de 42.399. En 2008 se registraron 286.254 salidas, 240.394 entradas, por lo que el saldo migratorio negativo fue de 45.860 (Tabla 2).

Tabla 2

Flujos migratorios, salidas e ingresos de ciudadanos ecuatorianos

\begin{tabular}{cccc}
\hline Año & Entradas & Salidas & Saldo migratorio \\
\hline 2000 & 355.836 & 504.203 & -148.367 \\
2001 & 404.636 & 553.244 & -148.608 \\
2002 & 448.113 & 589.086 & -140.973 \\
2003 & 456.295 & 581.401 & -125.106 \\
2004 & 536.779 & 606.494 & -69.715 \\
2005 & 598.722 & 660.799 & -62.077 \\
2006 & 656.309 & 740.833 & -84.524 \\
2007 & 752.684 & 795.083 & -42.399 \\
2008 & 240.394 & 286.254 & -45.860 \\
\hline
\end{tabular}

Fuente: Elaboración personal sobre la base del Perfil de la Migración Ecuatoriana de OIM, 2011.

Pasada la primera década del segundo milenio, Estados Unidos y España se mantuvieron como los destinos elegidos, aunque tomaron fuerza otros como Italia, Chile y Argentina (Figura 3). Por ejemplo, las últimas cifras de 2013 en España dan cuenta del descenso de esta migración a 390.034 personas ${ }^{9}$. Este viraje se debió a la imposición de un visado de ingreso al espacio Schengen de la Unión Europea a partir de junio de 2003, que desencadenó en la disminución de los flujos de ecuatorianos hacia el Viejo Mundo y la preeminencia de Estados Unidos como el destino buscado por los migrantes. Luego, en 2008, dentro del marco de políticas de control migratorio, el Parlamento de la Unión Europea aprobó la llamada Directiva Retorno que, entre otras particularidades, permite la detención de los inmigrantes irregulares hasta por un período de 18 meses mientras

9 La repatriación de ecuatorianos a su país de origen a través de la Directiva Retorno ha sido de 1.359 desde 2009 , solo superada por Bolivia (2.775), Brasil (1.697) y Argentina (1.683). 
se tramita su repatriación y la exclusión del retorno para los expulsados de hasta cinco años (Sassone, Medina y Cortés, 2011). Estas disposiciones afectan a aproximadamente 8.000.000 de indocumentados que viven en la Unión Europea, de los cuales un porcentaje importante - particularmente en España e Italia- son ecuatorianos ${ }^{10}$.

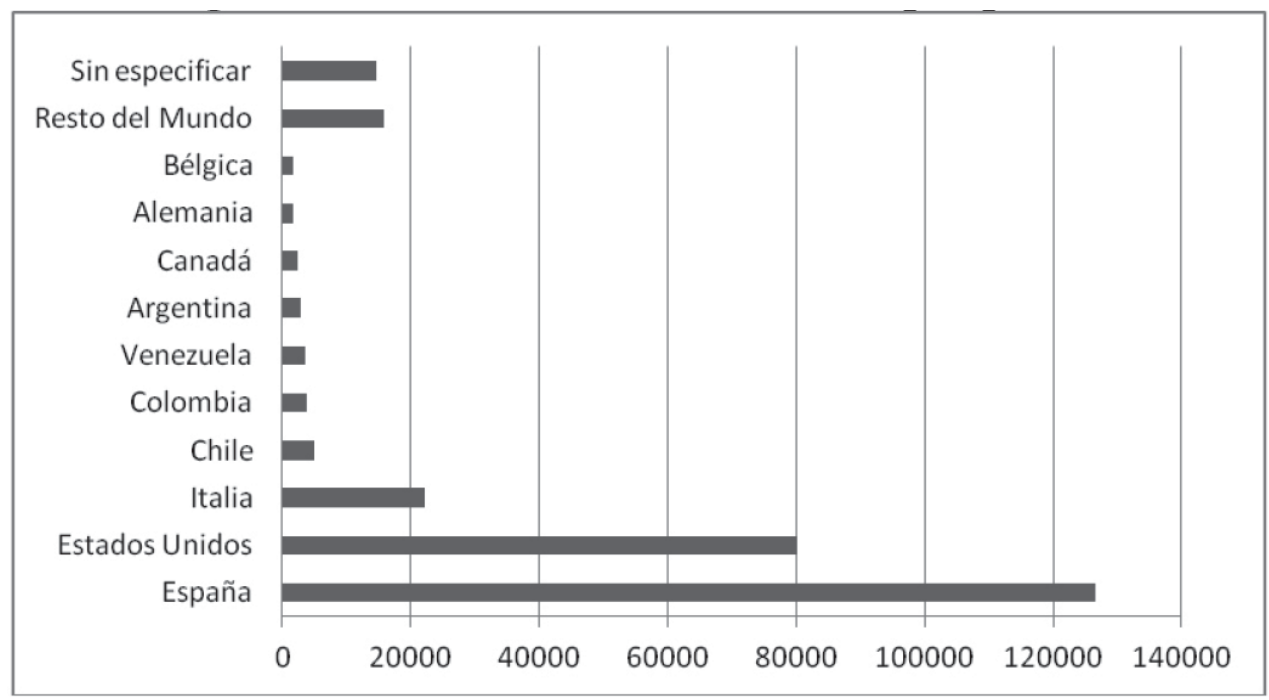

Figura 3. Emigrantes internacionales de Ecuador por país de residencia. Fuente: Elaboración personal sobre la base del Perfil Migratorio de Ecuador de OIM, 2011.

Este tránsito hacia los diversos destinos mundiales fue denominado "la estampida ecuatoriana" y se caracterizó por componerse de sectores medios y urbanos. Una de las principales razones para la emigración han sido las remesas, ya que se abandona la patria para mejorar la propia situación y la de los familiares que quedan en ella. Según datos de la encuesta nacional llevada a cabo para un estudio del Fondo Multilateral de Inversiones (FOMIN) del Banco Interamericano de Desarrollo (BID), el 83\% de los interrogados mencionó que una de las razones para salir del Ecuador es enviar dinero a sus familias y que estas puedan mejorar de manera significativa su vida. Según la OIM (2011), uno de los efectos macroeconómicos más visibles del envío de remesas es la disminución de las tasas de desempleo. Estas partidas han producido una reactivación económica, aunque

10 En 1985 se firmó en Schengen, Luxemburgo, un acuerdo por el que 26 países (Alemania, Austria, Bélgica, Dinamarca, Eslovaquia, Eslovenia, España, Finlandia, Francia, Grecia, Hungría, Islandia, Italia, Letonia, Liechtenstein, Lituania, Luxemburgo, Malta, Noruega, Países Bajos, Polonia, Portugal, Suecia y Suiza) abolieron los controles para la inmigración en sus fronteras interiores y los trasladaron a sus fronteras exteriores comunes. 
sin tener un impacto sustancial en el desarrollo del país. Por otra parte, el mercado laboral también se ha visto afectado pues los receptores de remesas participan menos de él y generan una "cultura rentista" en el país"

Otra de las características de la emigración ecuatoriana tiene que ver con la edad y con el nivel educativo de quienes migran. La mayoría de esta población posee entre 20 y 50 años y la mitad (el 46\%) tiene educación de nivel secundario. Debido a estas características en su formación, gran parte de los ecuatorianos migrantes - particularmente en España - se han convertido en proveedores de mano de obra barata que no requiere alta calificación: servicio doméstico, cuidado de menores y ancianos, hotelería, construcción, agricultura, entre las principales. Por último, cabe señalar que muchos expertos en la temática (Herrera, 2008; Gratton, 2005; Pedone, 2005) coinciden en que una de las particularidades de la migración ecuatoriana tiene que ver con su feminización, condición que ha dado lugar a la construcción de redes y la conformación de familias transnacionales.

\section{Ecuatorianos en Argentina: las causas para migrar}

Los ecuatorianos en Argentina llegan a un total de 3.000 según las cifras oficiales del Consulado del Ecuador en este país ${ }^{12}$, sin embargo, fuentes no oficiales contabilizan una cantidad de 7.000 u 8.000 personas que no están registradas. A modo de ejemplo, es para destacar que en las últimas elecciones para presidente que se celebraron en Ecuador el 17 de febrero de 2013, votaron 570 personas desde el Consulado de Buenos Aires.

Esta colectividad se caracteriza por ser flotante debido a que la mayoría de los migrantes son estudiantes que arriban al país para capacitarse y luego retornan al Ecuador. Los estudios "creativos" son los más elegidos por los ecuatorianos: Diseño Gráfico, Comunicación, Arte y Publicidad. En Ecuador estas carreras son muy costosas y no tienen el reconocimiento que poseen en las universidades argentinas como la Universidad de Buenos Aires (UBA) o la Universidad de Palermo (UP). Para tomar la decisión de migrar por estudios, el apoyo del Estado ecuatoriano se torna decisivo, pues brinda sustento a través de diversos programas de becas. El Instituto Ecuatoriano de Crédito Educativo y Becas

\footnotetext{
11 Durante el primer trimestre de 2008 se registró un ingreso de USD 759, 6 millones con un crecimiento estimado del $12,3 \%$ respecto a las remesas recibidas en el mismo período de 2007 . Se calcula que el $95,4 \%$ de las remesas provienen de España, Italia y Estados Unidos (Serrano, 2008).

12 Datos proporcionados por el cónsul del Ecuador en Argentina en diciembre de 2012.
} 
(IECE) abona mensualmente la cuota de la carrera de posgrado elegida por el becario, así como su vivienda y manutención. Luego existen las becas del Estado por intermedio de la Secretaría Nacional de Educación Superior, Ciencia, Tecnología e Innovación del Ecuador (SENESCYT). Estas subvenciones funcionan por convenio directo y tienen como requisito la devolución al Estado de las prestaciones en el momento de finalización de las capacitaciones, por ejemplo, a través del trabajo en instituciones o empresas estatales.

Asimismo, pareciera que se estimula la migración en pos de la formación educativa y capacitación también por parte del gobierno argentino. Justamente, en la última visita oficial del presidente Rafael Correa a la Argentina en diciembre de 2010 se firmaron acuerdos de cooperación económica, producción, cultura y defensa. Se reconocieron títulos y certificados de nivel inicial y secundario, así como de carreras de grado superior. Sin embargo, también la cantidad de estudiantes ecuatorianos ha mermado desde el año 2012 a causa de las políticas económicas implementadas por el gobierno del país austral como, por ejemplo, la imposibilidad de adquirir sin restricciones moneda extranjera.

[La cantidad de estudiantes] ha bajado. Cuando yo vine en 2005 en mi salón de clase, que éramos 30, 15 eran de Ecuador, el resto eran argentinos y unos pocos colombianos, pero porque el cambio nos recontra favorecía. Ahora con el dólar "blue" están las limitaciones de que no nos pueden enviar dinero tan fácilmente como antes, entonces tienen los pro $\mathrm{y}$ tienen los contras. Ahora las pocas veces que ahora he visto gente nueva, viene a hacer cosas más cortas, una maestría, un posgrado, un curso ejecutivo y ya no toda la carga de cuatro o cinco años como antes (Fernanda, comunicación personal, 12 de junio de 2012).

\section{Estrategias de inserción cultural de los ecuatorianos en Argentina}

Si bien pertenecen a una colectividad naciente, los ecuatorianos cuentan con diversas estrategias de inserción cultural como la gastronomía étnica, los medios de comunicación de migrantes (en especial Internet) y las actividades culturales y recreativas. Como en el caso colombiano, el Internet es un recurso fundamental en este grupo para la organización de actividades culturales como campeonatos de fútbol, eventos de NetWor$k_{i n g}{ }^{13}$, fiestas o la asistencia colectiva a grandes eventos como el torneo futbolístico Copa Libertadores de América (Figura 4).

13 Los Net Working de la Red de Profesionales Ecuatorianos en Argentina son eventos que establecen contactos entre profesionales con objetivo de organizar una red. Asimismo, tienen una función informativa para la colectividad. Son organizados por Andrea Ramírez (Red de Profesionales Ecuatorianos en Argentina). 


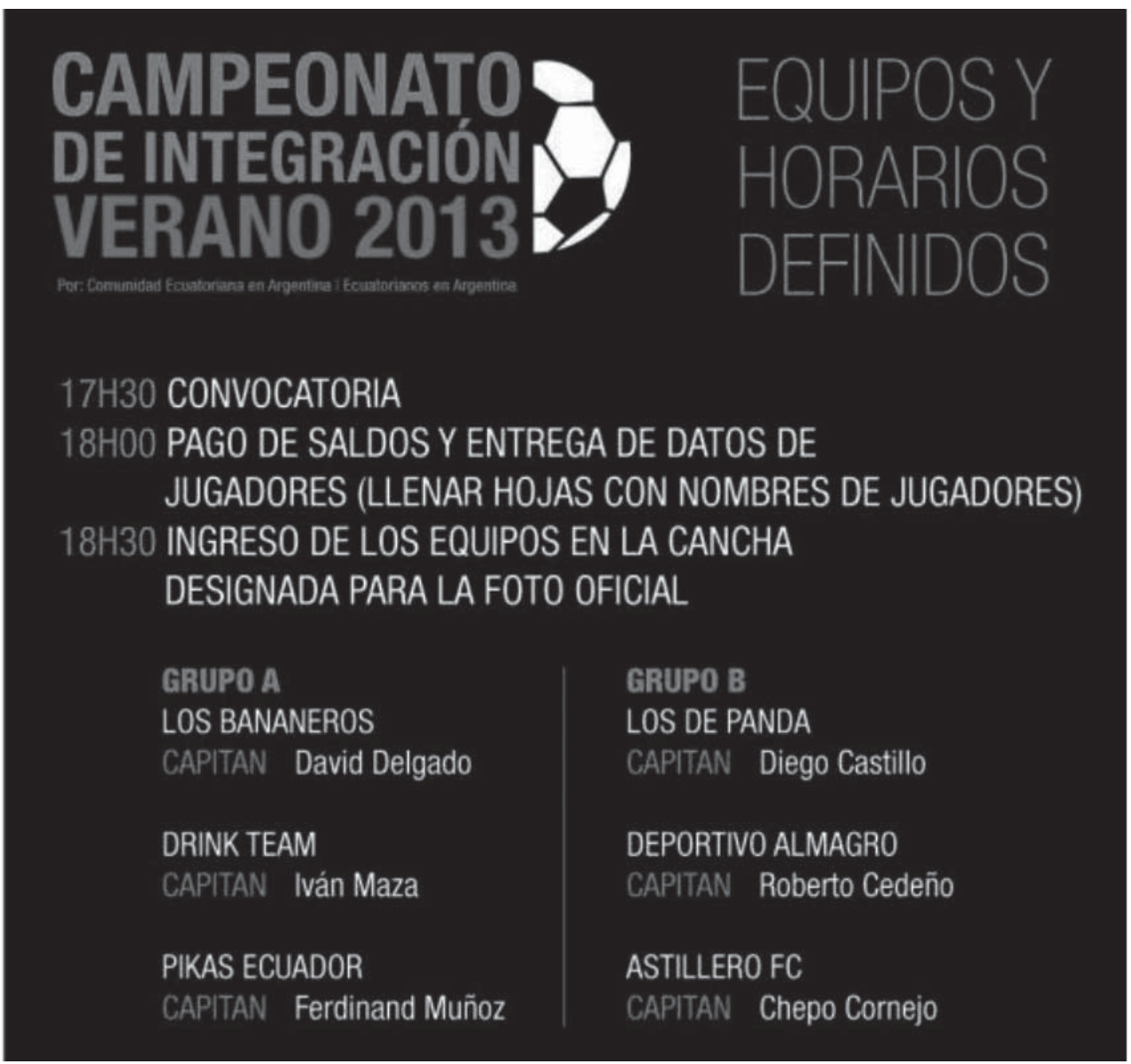

Figura 4. Actividades de inserción cultural de la comunidad ecuatoriana en Argentina. Fuente: Facebook Ecuatorianos en Argentina.

La web también sirve para el intercambio de información sobre prestaciones para el recién llegado a la Argentina, para el desarrollo de estrategias residenciales a través de consejos sobre alquileres de casas o apartamentos y para obtener información general y/o direcciones útiles sobre diversos servicios públicos. También, esta página brinda información sobre trámites migratorios o espacios para el ocio como restoranes y discotecas. Estas nuevas tecnologías se convierten en medulares debido a la particularidad de la migración ecuatoriana que posee pocas instituciones que excedan la Embajada y el Consulado de Ecuador en Argentina. Hemos recabado tres páginas de Internet de ecua- 
torianos en Argentina ${ }^{14}$, de las cuales se destaca Ecuatorianos en Argentina. Este sitio fue creado por Fernanda, una estudiante de Diseño y Publicidad de la Universidad de Palermo en 2009. Comenzó como un grupo de Facebook con el objetivo de brindar un servicio informativo a los connacionales que llegaban por primera vez a la Argentina con el objetivo de estudiar.

La página se nos ocurrió como hobbie, cada vez que veníamos para acá mi mamá o me papá me decían ahí va el hijo de Juanito y que lo ayudes a llevar no sé qué cosa o lo ayudes a hacer tal o cual trámite... Pero, bueno, ya empezábamos a trabajar y entonces no tenemos tiempo como para llevar a alguien a la recorrida.

Entonces creamos un grupito de Facebook y yo les contestaba desde el trabajo y así de a poquito de a poquito se fue ingresando, uno, dos, tres, cuatro y ahora son casi 3.000 personas (Fernanda, comunicación personal, 12 de junio de 2012).

La creación de este sitio es la materialización de las redes que tejen los migrantes y funciona como lazo - débil, en términos del sociólogo Mark Granovetter (1973) ${ }^{15}$ - al conectar a los pequeños grupos de ecuatorianos que residen en otras ciudades del país como La Plata y Córdoba, también centros universitarios. Como en el modelo colombiano, las asociaciones ecuatorianas son "nativas digitales" porque nacen exclusivamente en la red virtual y no preexisten físicamente en la sociedad. Estas se constituyen como medios de información y de servicios, así como recursos de visibilidad y espacios de construcción de identidades. Asimismo, se erigen como nexos que dan cuenta del aquí y el allá y organizan actividades que trascienden la red virtual como campeonatos de fútbol o los eventos de Net Working de la Red de Profesionales Ecuatorianos en Argentina y Ecuatorianos en Argentina. En consecuencia, podemos aseverar que las nuevas tecnologías han incrementado la creación de redes menos estructuradas y han acrecentado las ventajas estratégicas de quienes no tienen tantos recursos al reducir los costos en comunicación y coordinación (Finquelievich, 1999).

14 http://www.expat-blog.com/es/nacionalidades/ecuatoriano/en/america-del-sur/argentina, http://estudiarenargentina-mach.blogspot.com.ar/ y http://www.ecuatorianosenargentina.com.

15 Para Granovetter, las colectividades que permanecen más unidas y evidencian capacidad para actuar en conjunto son aquellas en las que hay una gran cantidad de lazos que conectan a los distintos grupos de individuos que las componen. Así, los grupos que tiene mayor conectividad son aquellos que poseen lazos débiles, es decir, que sus miembros no tienen un contacto asiduo sino ocasional con los otros grupos o individuos. Los periódicos y su acepción internautica se conforman como puentes entre los distintos subgrupos de cada colectividad (asociaciones, individuos, otros periódicos) y también por fuera de esta (Melella, 2013b). 
Finalmente, los ecuatorianos también cuentan con restoranes "étnicos" como Ecuador siete ocho siete, situado en el suburbio del Abasto en el barrio de Balvanera en la Ciudad Autónoma de Buenos Aires, o Rincón Ecuatoriano, en el barrio porteño de Montserrat. Este último pertenece a Fredda Montaño, quien es una referente de la colectividad ecuatoriana en la Argentina. "Mamá Fredda", como le dicen los ecuatorianos, llegó a la Argentina en 1993 con el grupo de danza Bejuco. Luego de vivir en Mar de Plata, Fredda se instaló en Buenos Aires, donde tiene un restorán y un conjunto de música y danzas afroamericanas y es convocada por diversas organizaciones y autoridades estatales para representar al Ecuador en Argentina.

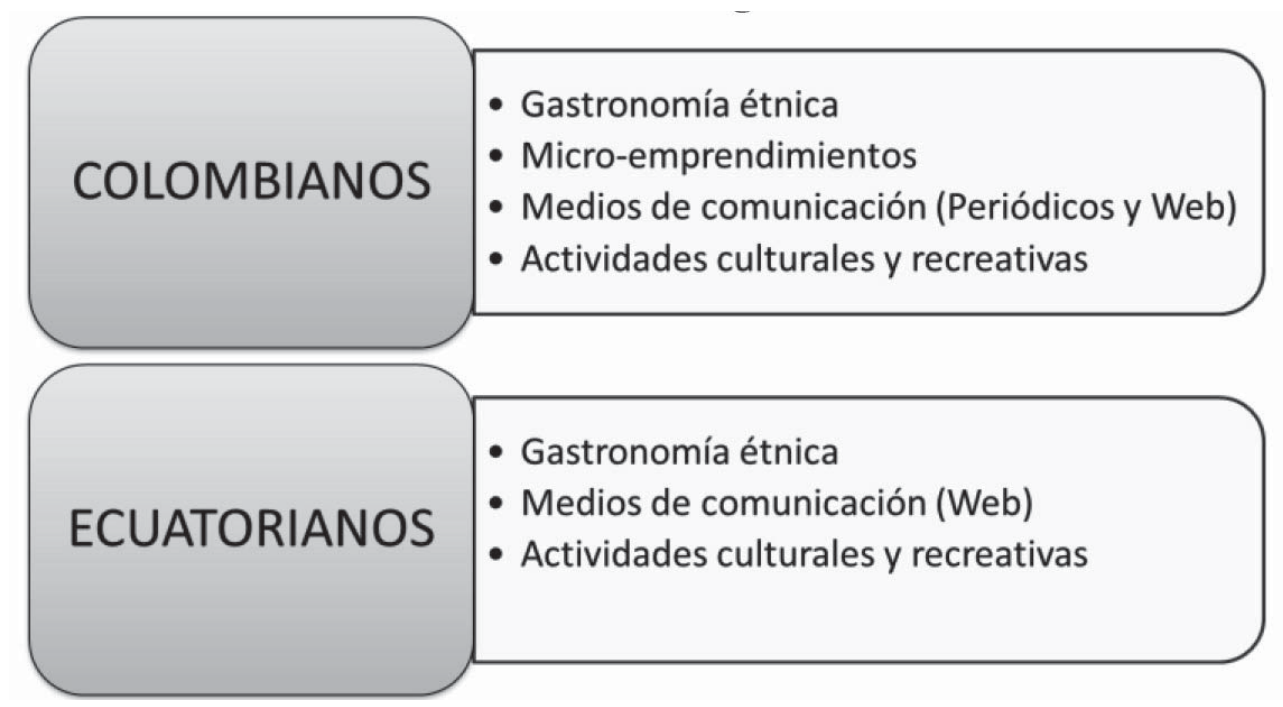

Figura 5. Estrategias de inserción cultural de la colectividad colombiana y ecuatoriana en Argentina. Fuente: Elaboración personal. 


\section{Conclusiones}

Colombia y Ecuador son países que han tenido una emigración constante aunque fluctuante por períodos a lo largo de su historia. Las emigraciones hacia Argentina no responden a los mismos motivos que las que tienen como destino Europa y Estados Unidos. Las primeras tienden a ser voluntarias, motivadas por la búsqueda de capacitación y perfeccionamiento; las segundas son más bien por motivos económicos-laborales. Ambos destinos acogen refugiados políticos y víctimas de la violencia.

La particularidad del caso argentino radica en que la mayor parte de estos migrantes son jóvenes y no buscan una residencia definitiva (más allá de los casos de refugio). Sin embargo, resulta interesante entender, por un lado, la migración como un proceso de articulación de espacios geopolíticos y culturales en pos de la conformación de redes transnacionales; por otro, las actividades gastronómicas, los microemprendimientos comerciales, los medios de comunicación de migrantes y el desarrollo de actividades culturales y deportivas como estrategias primordiales de inserción cultural en destino. Estas prácticas tienen la particularidad de haber sido desarrolladas por dos grupos que no están asentados espacialmente en la ciudad como otras colectividades con más arraigo como las europeas meridionales, la paraguaya, boliviana o peruana, entre otras.

El desarrollo de acciones sociales diversas cuya dimensión cultural implica una diferencia situada sienta las bases para la identificación de cada grupo y para su desarrollo en la sociedad de destino. Estas prácticas, entendidas como estrategias de inserción cultural, implican negociaciones y conflictos y promueven relaciones intra e interculturales donde diversos individuos y grupos dialogan, interactúan, se mezclan y conviven. Tener en cuenta este tipo de iniciativas de los grupos migratorios, desde una perspectiva dinámica entre la cultura y las culturas que suponga superar los esencialismos, permite contribuir a la concreción (de parte de los Estados nacionales o las organizaciones no gubernamentales) de una comunicación intercultural en el contexto de las grandes ciudades globalizadas. Asimismo, este trabajo responde a una línea de investigación en el campo migratorio que presenta al campo cultural como espacio para la recuperación de las experiencias migratorias y pone en evidencia la necesidad de abordaje del fenómeno migratorio desde un enfoque trasversal e interdisciplinario.

Es importante destacar el papel central que cumplen las TIC en la conformación de estos espacios culturales. En ambas colectividades hemos observado que el Internet es un medio muy utilizado para dar a conocer informaciones de los países de origen, ayudar al recién llegado, promocionar sus microemprendimientos y eventos culturales, así como 
para crear lazos comunitarios, promover visibilidad, generar espacios de conformación de identidades y promover el establecimiento de comunidades diaspóricas. Las comunidades en la web de ecuatorianos y colombianos crean lazos, mientras que las de otros grupos más afincados como europeos, bolivianos o paraguayos afianzan los existentes. Las TIC se configuran como una herramienta fundamental para los migrantes que no poseen redes fuertes como producto del asiento en las sociedades de destino como el caso de las migraciones estudiadas. Por último, la construcción de un espacio cultural migratorio parece adentrarse cada vez más hacia un escenario marcado por la virtualidad. El ciberespacio se proyecta como el nuevo escenario de despliegue de lo biográfico en el que confluyen las narraciones de experiencias migratorias individuales y sociales. Hace tiempo Enrique Oteiza (2010) decía que la migración implicaba más que un viaje internacional. Hoy, categorías como tiempo y espacio, aquí y allá, parecieran no bastar para pensar las estrategias culturales de la migración en un paradigma caracterizado por la conectividad sistémica.

\section{Referencias}

Altamirano, T. (1983). Migración y estrategias de supervivencia de origen rural entre los campesinos de la ciudad. Revista Anthropologica, 1. Recuperado de http://revistas.pucp. edu.pe/index.php/anthropologica/article/view/6309/6353

Appadurai, A. (2001). La modernidad desbordada. Dimensiones culturales de la globalización. Buenos Aires, Argentina: Fondo de Cultura Económica.

Arfuch, L. (2010). El espacio biográfico. Dilemas de la subjetividad contemporánea. Buenos Aires, Argentina: Fondo de Cultura Económica.

Baby Collin, V., Cortes, G., Miret, N y Sassone, S. (2010). Visibilidad de la migración boliviana en Madrid, Barcelona, Buenos Aires: un análisis comparado. Actas del XII Congreso de Población Española. Población y espacios urbanos. Facultad de Geografía i Historia de la Universitat de Barcelona. Recuperado de http://www.ub.edu/congreso_poblacion/ docs/actas.pdf

Barth, F. (1976). Los grupos étnicos y sus fronteras. Ciudad de México, México: Fondo de Cultura Económica. 
Benencia, R. (2004). La inmigración limítrofe. En F. Devoto, Historia de la inmigración en la Argentina (pp. 433-484). Buenos Aires, Argentina: Sudamericana.

Caggiano, S. (2005). Lo que no entra en el crisol. Inmigración boliviana, comunicación intercultural y procesos identitarios. Buenos Aires, Argentina: Prometeo.

Canales, A. y Zlolniski, C. (septiembre de 2000). Comunidades transnacionales y migración en la era de la globalización. Simposio sobre Migración Internacional en Las Américas. 4, 5 y 6 de septiembre de 2000, San José, Costa Rica. Recuperado de http://www.eclac. cl/publicaciones/xml/2/8852/lcg2124P_7.pdf

Castillo, J. y Gurrieri, J. (2012). El panorama de las migraciones limítrofes el Perú en la Argentina en el inicio del siglo XXI. Cuadernos Migratorio, 2, 17-49.

Cárdenas, M. y Mejía, C. (2006). Migraciones internacionales en Colombia: ¿qué sabemos? Working Papers Series, 30. Recuperado de http://www.iadb.org/intal/intalcdi/ PE/2009/02989.pdf

Cavalcanti, L. (2008). Negocios étnicos: importación y repercusiones de una categoría. En E. Santamaría (Ed.), Retos epistemológicos de las migraciones transnacionales (pp. 217236). Barcelona, España: Antrophos.

Cortez, D. (2004). Los discursos de la "ecuatorianidad" en revistas de inmigrantes. Revista Aportes Andinos, 12. Recuperado de http://www.uasb.edu.ec/padh/revista12/migracion/ponencias/david\%20cortez.htm

Devoto, F. (2004). Historia de la inmigración en la Argentina. Buenos Aires, Argentina: Sudamericana.

Diminescu, D. (2011). El migrante conectado. Por un manifiesto epistemológico. En V. Hernández, C. Mera y E. Oteiza (Comp.), Circulación de saberes y movilidades internacionales: perspectiva latinoamericana (pp. 201-216). Buenos Aires, Argentina: Biblos.

Dirección Nacional de Migraciones (DNA) (2011). Nosotros, los que vinieron. Volumen 1. Buenos Aires, Argentina: Gráfica Argentina.

Duque, J. y Raffani, D. (2009). Inmigración en Argentina. Entre Europa y América Latina: el caso colombiano. Temas de Nuestra América, 1 (48), 65-75. 
Finquelievich, S. (1999). Del café de barrio a las redes electrónicas. Las comunidades virtuales como actores sociales en las ciudades. Revista Kairós, 4. Recuperado de http://www. revistakairos.org/k04-d02.htm

Garay, L. J. y Rodríguez, A. (2005). La emigración internacional en Colombia: una visión panorámica a partir de la recepción de remesas. Ministerio de Relaciones Exteriores, Organización Internacional para las Migraciones, Bogotá. Recuperado de http://www. almamater.edu.co/sitio/Archivos/Documentos/Documentos/00000023.pdf

Gómez-Escalonilla, G. (Comp.). (2008). Voces de la inmigración. Medios latinos en Madrid. Madrid, España: Universitas.

Gómez, C. (2009). L'importance de la visibilité dans les processus migratoires. Papers, 91, 153-169.

Granovetter, M. (1973). The strength of weak ties. American Journal of Sociology, 78 (6), $1.360-1.380$.

Gratton, B. (2005). Ecuador en la historia de la migración internacional. ¿Modelo o aberración? En G. Herrera, M. C. Carrillo y A. Torres (Eds.), La migración ecuatoriana: transnacionalismo, redes e identidades (pp. 31-55). Quito, Ecuador: FLACSO.

Grimson, A. (1999). Relatos de la diferencia y la igualdad. Los bolivianos en Buenos Aires. Buenos Aires, Argentina: Eudeba.

Guarnizo, L. (2006). El Estado y la migración global colombiana. Migración y Desarrollo, 6, 79-101.

Hernández, M. (2010). Migración colombiana en la Argentina. II Seminario Internacional Políticas de la Memoria. Centro Cultural de la Memoria Haroldo Conti, 5 al 7 de octubre de 2009, Buenos Aires, Argentina. Recuperado de http://www.derhuman.jus.gov.ar/ conti/2010/10/mesa-04/hernandez_mesa_4.pdf

__——. (2011). Colombianos en Argentina: memorias del conflicto armado y experiencia migratoria. Estudios Sociales, 8, 189-201.

Herrera, G. (2008). Mujeres ecuatorianas en el trabajo doméstico en España. Prácticas y representaciones de exclusión e inclusión. En S. Novick (Comp.), Las migraciones en 
América Latina. Políticas, culturas y estrategias (pp. 73-92). Buenos Aires, Argentina: Catálogos-CLACSO.

Herrera, G., Moncayo, M. y Escobar, A. (2011). Perfil Migratorio Ecuador 2011. Quito, Ecuador: Organización Internacional para las Migraciones OIM.

Instituto Nacional de Estadística y Censos (INDEC) (2001). Censo Nacional de Población, Hogares y Viviendas 2001. Buenos Aires, Argentina: INDEC.

-_—_. (2010). Censo Nacional de Población, Hogares y Viviendas 2010. Recuperado de http://www.censo2010.indec.gov.ar/cuadrosDefinitivos/analisis_censo_feb12.pdf

Jokisch, B. y Kyle, D. (2005). Las transformaciones de la migración transnacional del Ecuador, 1993-2003. En G. Herrera, M. C. Carrillo y A. Torres (Eds.), La migración ecuatoriana: transnacionalismo, redes e identidades (pp. 57-69). Quito, Ecuador: FLACSO.

Levitt, P., De Wind, J. y Vertovec, S. (2003). International perspectives on transnational migration: An introduction. International Migration Review, 37, 565-575.

López, G. y Ciuffoli, C. (2012). Facebook es el mensaje. Oralidad, escritura y después. Buenos Aires, Argentina: Ediciones La Crujía.

Malgesini, G. y Giménez, C. (2000). Guía de conceptos sobre migraciones, racismo e interculturalidad. Madrid, España: Catarata.

Martínez, J. (2003). El mapa migratorio de América Latina y el Caribe, las mujeres y el género. Serie Población y Desarrollo. Santiago, Chile: CEPAL.

. (Ed.) (2011). Migración internacional en América Latina y el Caribe. Nuevas tendencias, nuevos enfoques. Comisión Económica para América Latina y el Caribe (CEPAL). Recuperado de http://www.cepal.org/publicaciones/xml/4/43634/lcr2170.pdf

Ministerio del Interior y Dirección Nacional de Migraciones (2011). Nosotros, los que vinieron. Testimonios de vida de inmigrantes, Vol. 1. Buenos Aires, Argentina: Dirección Nacional de Migraciones.

Melella, C. (2012). La prensa migrante en la Argentina. Recurso de visibilidad y construcción de identidades: el caso del periódico Renacer, de y para la colectividad boliviana. Saarbrücken, Alemania: Editorial Académica Española. 
- - - (2013a). Migración y tecnologías de la información y la comunicación (TIC). De la prensa gráfica a las redes virtuales como espacios de construcción identitaria de los migrantes de países andinos en la Argentina. Tesis de Doctorado. Universidad de Buenos Aires, Argentina.

- (2013b). Migración y tecnologías de la información y de la comunicación (TIC). La presencia de los periódicos de migrantes en Internet y los desafíos del análisis de las redes sociales virtuales. Cuadernos de H Ideas, 7 (7). Recuperado de http://perio.unlp. edu.ar/ojs/index.php/cps/article/view/1784/1776

Novick, S. (2008). Migración y políticas en Argentina: tres leyes para un país extenso (18762004). En S. Novick (Comp.), Las migraciones en América Latina. Políticas, culturas y estrategias (pp. 131-151). Buenos Aires, Argentina: Catálogos-CLACSO.

Oleas, S. y Hurtado, F. (2011). Flujos migratorios en Ecuador. 1950-2007. Quito, Ecuador: Cordes.

Organización Internacional para las Migraciones (OIM) (2011). Informe sobre las migraciones en el mundo. Comunicar eficazmente sobre la migración en el mundo. Recuperado de http://publications.iom.int/bookstore/free/WMR2011_Spanish.pdf

__—_. (2012). Perfil migratorio de Argentina. Recuperado de http://www.iom.int/files/live/ sites/iom/files/pbn/docs/Perfil-Migratorio-de-argentina-2012.pdf

Oteiza, E. (Comp.) (2010). Patrones migratorios internacionales en América Latina. Buenos Aires, Argentina: Eudeba.

Pedone, C. (2005). Tú siempre jalas a los tuyos. Cadenas y redes migratorias de las familias ecuatorianas en España. En G. Herrera, M. C. Carrillo y A. Torres (Eds.), La migración ecuatoriana: transnacionalismo, redes e identidades (pp.105-143). Quito, Ecuador: FLACSO.

Pellegrino, A. (2010). Tendencias de la migración internacional en América Latina y el Caribe en la segunda mitad del siglo XX. En E. Oteiza (Comp.), Patrones migratorios internacionales en América Latina (pp. 27-46). Buenos Aires, Argentina: Eudeba.

Portes, A. (1978). Migration and under development. Politics and Society, 8, 1-48. 
. (2005). Convergencias teóricas y evidencias empíricas en el estudio del transnacionalismo de los inmigrantes. Migración y Desarrollo, 4, 2-19.

Puente, M. (2011). Cuando migrar es la opción. Estudiantes colombianos en Argentina: motivos y experiencias en sus trayectorias migratorias y estudiantiles. Tesis de Maestría, Universidad de Buenos Aires, Argentina.

Ramírez, C., Zuluaga, M. y Perilla, C. (2010). Perfil Migratorio de Colombia. Bogotá, Colombia: Organización Internacional para las Migraciones. Recuperado de http://es.scribd. com/doc/55185974/Perfil-Migratorio-de-Colombia-2010

Sassone, S. (2006). Migración, territorio e identidad cultural: construcción de lugares bolivianos en la ciudad de Buenos Aires. Revista Población de Buenos Aires, 4, 9-28.

Sassone, S., Medina, L. y Cortes, G. (2011). Dinámicas migratorias y reconfiguraciones territoriales 'en y desde' América Latina: ¿hacia un nuevo modelo? En V. Hernández, C. Mera, J. B. Meyer y E. Oteiza (Eds.), Circulación de saberes y movilidades internacionales: perspectivas latinoamericanas (pp. 39-52). Buenos Aires, Argentina: Biblos.

Serrano, A. (2008). Perfil Migratorio del Ecuador. Quito, Ecuador: Organización Internacional para las Migraciones.

Steimberg, O. (1993). Semiótica de los medios masivos. Buenos Aires, Argentina: Atuel.

Verón, E. (1993). La semiosis social. Fragmentos de una teoría de la discursividad. Barcelona, España: Gedisa.

Villa, M. (2008). Políticas públicas sobre el desplazamiento forzado en Colombia: una lectura desde las representaciones sociales. En S. Novick (Comp.), Las migraciones en América Latina. Políticas, culturas y estrategias (pp. 229-248). Buenos Aires, Argentina: Catálogos-CLACSO. 